\title{
Silencioso e penetrante: o processo de financeirização a partii das instituições promotoras da inclusão financeira ${ }^{1}$
}

Márcia Pereira Cunha²

Resumo: Este artigo tem o objetivo de apresentar a rede de organizações que, hoje, atua para implementar a chamada inclusão financeira. Essa cadeia se estrutura internacionalmente e estabelece relações ad hoc com diversos países do globo. Estimula e apoia ações para a criação e circulação de produtos e serviços financeiros para a população pobre com a justificativa de promoção de seu bem-estar e proteção. A análise se baseia em pesquisa documental e dedica-se ao caso brasileiro. Caracteriza a ramificação de atuação e instituições envolvidas na disseminação desse ideário e oferece elementos para reflexão a respeito de seus efeitos sociais.

Palavras-chave: Inclusão Financeira; Bancarização; Parceria Nacional para Inclusão Financeira; Pobreza.

\section{SILENT AND PENETRATING: THE PROCESS OF FINANCIALIZATION FROM THE INSTITUTIONS THAT PROMOTE FINANCIAL INCLUSION}

Abstract: This article aims to present the network of organizations that today acts to implement the so-called financial inclusion. This chain is structured

1 Este artigo resulta de pesquisa financiada pelo Programa Nacional de Pós-Doutorado da Capes (PNPDCapes), realizada no Departamento de Sociologia da Unicamp.

2 Departamento de Sociologia do Instituto de Filosofia e Ciências Humanas - Universidade Estadual de Campinas (IFCH-Unicamp) - Campinas - Brasil - marcia.cunha@gmail.com 
internationally and establish ad hoc relations with several countries of the globe. It stimulates and supports the creation and circulation of financial products and services to the poor on the grounds of promoting their welfare and protection. The analysis is based on documental research and is dedicated to the Brazilian case. It features the branch of activity and institutions involved in the dissemination of this ideology and offers insights for thinking about its social effects.

Keywords: Financial Inclusion; Bancarização; Global Partnership for Financial Inclusion; Poverty.

\section{Introducç̃o}

A variedade de fenômenos apreendidos sob o termo "financeirização" é grande. Os campos de investigação que tomam a financeirização como objeto são igualmente variados. Em termos econômicos, a financeirização tende a ser definida como a hipertrofia desse campo específico - o das finanças - frente a outros setores de atividade econômica, em especial o industrial (Duménil; Lévy, 2005; Kripner, 2005). Em estudos sociológicos, como os de Lemoine (2014) ou Chiapello (2015), a financeirização assume a forma de presença ou entrada de agentes, objetos, práticas, instrumentos ou lógica oriundos dos mercados financeiros nos mais diversos âmbitos das vidas privada e social, alterando-lhes, assim, dinâmicas, organizações, valores. Análises no nível das relações individuais abordam o tema por meio do endividamento de famílias em contextos tão diversos quanto o de domicílios pobres no Chile (Han, 2012) ou de classe média norte-americanos (Fligstein; Goldstein, 2013). A financeirização, nesses casos, designa práticas que ganham impulso pelo fácil acesso a produtos e serviços financeiros, incidindo sobre as formas de organização da vida cotidiana, das relações familiares e destas com seu entorno.

É nesse sentido que caminham investigações sobre o processo de financeirização no âmbito das instituições públicas e políticas sociais. Trumbull (2012) desenvolve um aspecto presente nos estudos sobre endividamento, que é a recorrência a crédito em um contexto de fragilização ou supressão de estruturas de proteção social, levando a uma compreensão de, usando suas palavras, crédito como bem-estar. Lavinas (2015), tratando do nível macroinstitucional, define o processo de financeirização da política social como transformação da renda transferida por diferentes políticas em garantia, no mercado, para os vendedores desses produtos e serviços financeiros. Nesses estudos, por sua vez, o contexto internacional também ajuda a localizar o problema, uma vez que o ambiente externo influencia de maneira bastante importante as orientações adotadas internamente e as políticas sociais não são exceção a essa regra. Weber (2004) não 
só considera esta influência, como problematiza enquadramentos que ela chama de "estadocêntricos" da questão e descreve a relação entre o social e o financeiro como mais íntima do que pode parecer. No primeiro ponto, defende considerar as tomadas de decisão e jogos de poder entre grupos de interesse globalmente definidos e não divididos em dicotomias, como países do Norte-Sul ou planos internacional-doméstico, isto é, há alianças entre grupos de países pobres e ricos que não se definem por divisões nacionais, mas pelo lugar ocupado na configuração dos interesses econômicos e políticos organizados de forma global. No segundo caso, observando o investimento do Banco Mundial em programas de microcrédito com fins de enfrentamento da pobreza, mostra como intervenções aparentemente restritas a este universo terminam produzindo resultados úteis para objetivos bem mais abrangentes de liberalização das finanças no mundo.

Este artigo objetiva acrescentar mais uma peça na construção deste cenário: como se estruturam, hoje, as ações de organizações internacionais que concorrem para a introdução das finanças no cotidiano de indivíduos e famílias pobres e, mais, como a produção dessas ideias e diretrizes entram no Brasil nos anos 2000, combinando-se a políticas locais. No discurso internacional, as experiências de concessão de crédito aos chamados pequenos empreendedores - o microcrédito - são centrais. Como veremos, embora aqui o microcrédito tenha sido alvo de investimento e transformações, assim como ocorreu em outros países, o fato que acopla o Brasil a esse cenário de maneira definitiva é o desenvolvimento das políticas de transferência condicionada de renda ou, de forma mais específica, o Programa Bolsa Família. É por meio dele que o Brasil é situado no campo discursivo e de intervenções reunidas sob o título de inclusão financeira, que, por sua vez, se define pela oferta de produtos e serviços financeiros a indivíduos e famílias pobres - em especial micropoupança, microsseguros e microcrédito - como meio de garantia de proteção e bem-estar social. ${ }^{3}$ A criação e oferta desses produtos e serviços é acompanhada, ainda, por um rol de ações designado como educação financeira, liderado no plano internacional pela OCDE (Organização para Cooperação e Desenvolvimento Econômico) e no Brasil por um conjunto de instituições públicas e privadas ligadas ao meio financeiro.

Nesse sentido, adotamos a perspectiva de que a proposição de compra de uma proteção há não muito tempo sustentada sobre noções de pacto social (mesmo com níveis diferentes de concretização entre países) é um passo adiante no processo mais amplo de investida contra sistemas e políticas de bem-estar públicos. Os artífices da inclusão financeira colocam-na como alternativa no

3 Com base na experiência de países diferentes, Bateman (2010) e Seibel (2005) chamam a atenção para a progressiva substituição do termo microcrédito pelo de microfinanças e posterior emprego deste último (inicialmente como sinônimo do primeiro) em sentido mais genérico, para referência a ramos de atividades distintas, como micropoupança e microsseguros. 
clarão aberto por este desmoronamento e a educação financeira como sua pedagogia, ambas incidindo sobre os contextos nacionais em transformação. A natureza transnacional e financeira do empreendimento é marca do tempo em que ele se realiza, de intensificação de fenômenos que não se limitam às fronteiras nacionais e que são afetados pelas decorrências do desenvolvimento das finanças. Acreditamos ser profícuo considerar essas dimensões na reflexão acerca das novas políticas sociais e de seus fundamentos, colocando-as em perspectiva que não se confunde com a avaliação de seus resultados no nível local.

Em função da ampla gama de atores institucionais - nacionais e internacionais, públicos e privados - envolvidos na disseminação da inclusão financeira, serão apresentados aqueles considerados mais importantes, suas linhas de atuação e, com maior detalhamento, uma passagem específica: a bancarização. Isso porque a bancarização é um requisito para o alcance desta população pelo setor financeiro (não só no presente brasileiro, mas também nos casos de microcrédito na Ásia, África e América Latina do fim da década de 1980). A escolha das instituições orientou também a seleção dos documentos consultados. Sua leitura seguiu a ordem cronológica das publicações, sendo privilegiados documentos de fundação, de estabelecimento de princípios e diretrizes, planos de ação e relatórios de atividades. $\mathrm{O}$ critério cronológico se justifica pelo fato de tratarmos de discursos e composição organizacional recentes, em que se flagram mudanças e continuidades relevantes tanto para a caracterização dos objetos, quanto para a sua leitura e interpretação. $\mathrm{O}$ critério relativo ao tipo de documento baseia-se na apresentação pretensamente consolidada, por eles, do discurso institucional e descrição de seus desdobramentos em objetivos e ações concretas.

\section{Muitas agendas em uma: a bandeira da Inclusão Financeira}

A agenda internacional para Inclusão Financeira remete a encontro do G2o, em setembro de 2009, em Pittsburgh, quando foi constituído o Grupo de Experts para Inclusão Financeira (FIEG), com objetivo de "apoiar a segura e ampla difusão de novos modos de prestação de serviços financeiros capazes de alcançar os pobres e, com base no exemplo da microfinança, dar escala a modelos bem-sucedidos de financiamento de pequenas e médias empresas" (G20, 2009: s/p.). Depois de um ano de trabalho, o FIEG foi extinto para dar lugar à Parceria Global para Inclusão Financeira (GPFI), descrita em seus documentos oficiais como uma "plataforma inclusiva", que reúne países do G20, mas também outros países e parceiros interessados em desenvolver ações de inclusão financeira. Mais concretamente, a GPFI é formada por um conjunto de instituições privadas e agências multilaterais (Quadro 1), que estabelecem relações com instâncias governamentais e privadas dos países em que desejam atuar. 
Quadro 1 - Instituições agregadas à Parceria Global para Inclusão Financeira (2010-2014)

\begin{tabular}{|c|c|}
\hline Organizações & Natureza $^{4}$ \\
\hline $\begin{array}{l}\text { Aliança para } \\
\text { Inclusão } \\
\text { Financeira (AFI) } \\
\text { (a) (b) }\end{array}$ & $\begin{array}{l}\text { Rede de bancos centrais e outras agências reguladoras de países } \\
\text { em desenvolvimento. Criada em } 2008 \text { com objetivo de partilhar } \\
\text { conhecimento sobre inclusão financeira de pobres. Em maio de } 2015 \\
\text { contava com instituições de } 96 \text { países. }\end{array}$ \\
\hline $\begin{array}{l}\text { Grupo Consultivo } \\
\text { de Assistência aos } \\
\text { Pobres (CGAP) } \\
\text { (a) (b) }\end{array}$ & $\begin{array}{l}\text { O CGAP foi criado em 1995, sediado no Banco Mundial, com o objetivo } \\
\text { de desenvolver pesquisas e experiências envolvendo prestadores de } \\
\text { serviços financeiros, financiadores e formuladores de políticas públicas } \\
\text { para a promoção de acesso a serviços financeiros por populações pobres. } \\
\text { Segundo site do Grupo, contava, em 2015, com "mais de } 30 \text { agências de } \\
\text { desenvolvimento, fundações privadas e governos nacionais". }\end{array}$ \\
\hline $\begin{array}{l}\text { International } \\
\text { Finance } \\
\text { Corporation (IFC) } \\
\text { (b) }\end{array}$ & $\begin{array}{l}\text { Instituição membro do grupo do Banco Mundial com foco de atuação } \\
\text { exclusivamente voltado para o setor privado. Com objetivo de fomentar } \\
\text { crescimento econômico sustentável de países em desenvolvimento, } \\
\text { financia investimentos do setor privado, mobiliza capital em mercados } \\
\text { financeiros internacionais e oferece consultoria para governos e empresas. }\end{array}$ \\
\hline $\begin{array}{l}\text { Aliança Better } \\
\text { than Cash }\end{array}$ & $\begin{array}{l}\text { Rede formada por governos, empresas privadas e organizações para } \\
\text { o desenvolvimento com o objetivo de promover a substituição de } \\
\text { pagamentos em dinheiro por pagamentos por meio eletrônico em ações } \\
\text { tão diversas quanto pagamento de benefícios, ajuda humanitária ou } \\
\text { transações entre governos e setor privado. Criada em 2012, é financiada } \\
\text { pela Fundação Bill e Melinda Gates, Citi, Fundação Ford, Mastercard, } \\
\text { Rede Omidyar, USAID e Visa Inc. }\end{array}$ \\
\hline $\begin{array}{l}\text { Fundo } \\
\text { Internacional } \\
\text { para o } \\
\text { Desenvolvimento } \\
\text { Agrícola (IFAD) }\end{array}$ & $\begin{array}{l}\text { Agência das Nações Unidas, criada em 1977, como instituição financeira } \\
\text { internacional para a erradicação da pobreza rural e promoção de } \\
\text { segurança alimentar em países em desenvolvimento. }\end{array}$ \\
\hline $\begin{array}{l}\text { Organização para } \\
\text { Cooperação e } \\
\text { Desenvolvimento } \\
\text { Econômico } \\
\text { (OCDE) }\end{array}$ & $\begin{array}{l}\text { Organização criada em 1960, com objetivo de promoção de crescimento } \\
\text { sustentável, formada, hoje, por } 34 \text { países membros. }\end{array}$ \\
\hline Banco Mundial & $\begin{array}{l}\text { Instituição criada em } 1944 \text { para assistir financeira e tecnicamente } \\
\text { a reconstrução dos países afetados pela guerra, tendo expandido e } \\
\text { diversificado suas formas de atuação. }\end{array}$ \\
\hline
\end{tabular}

Fonte: <https://www.gpfi.org/implementing-partners> . Acesso em: 27 mar. 2015.

(a) Citadas, ao lado da Fundação Bill e Melinda Gates, como apoiadoras da Parceria Nacional para Inclusão Financeira, em seus documentos.

(b) Citadas como parceiras implementadoras da GPFI, em seus documentos.

4 As descrições resultam de síntese de apresentações feitas pelas próprias instituições em seus sites e publicações e presentes no site da GPFI. Acessos entre dezembro de 2014 e março de 2015. 
O Brasil acompanhou de perto esse modelo, criando seu equivalente nacional, a Parceria Nacional para Inclusão Financeira (PNIF), em 2011, sob liderança do Banco Central do Brasil e formalizando iniciativas que já vinham sendo desenvolvidas pelo menos desde 2009. A Parceria Nacional é orientada por três objetivos:

Expandir e melhorar o acesso da população a serviços financeiros; favorecer a responsabilidade financeira e o acesso a informações sobre serviços financeiros, por meio da educação financeira e do aumento da transparência; atuar para que a oferta de serviços financeiros seja mais adequada às necessidades da economia e da população (PNIF, 2012: s/p.).

Também como a Parceria Global, em 2010, a Parceria Nacional elaborou um plano de ação em 2012. As organizações internas de uma e de outra, no entanto, são diversas. No caso da Parceria Nacional, o Plano de Ação para Fortalecimento Institucional deu o norte: dividido em três eixos ("Regulação" "Educação e Transparência" e "Diagnóstico"), identificou órgãos e instituições públicas e privadas com atuação nas áreas pertinentes e os agregou às respectivas ações previstas. A Parceria Global foi estruturada em subgrupos temáticos (Quadro 2) e os Planos de Ação para Inclusão Financeira (FIAP) - versões 2010 e atualizada, 2014 - organizam suas ações segundo as áreas por eles designadas, sem menção explícita às instituições da GPFI. Esta característica contribui com a extraordinária ramificação de linhas de ação e incorporação de organizações que não pertencem diretamente à GPFI, mas que se juntam a ela em ações específicas, criando uma rede de instituições extensa e de crescimento potencialmente ilimitado.

Quadro 2 - Subgrupos da GPFI

\begin{tabular}{|l|c|l|}
\hline \multicolumn{1}{|c|}{ Subgrupo } & Criado em & \multicolumn{1}{|c|}{ Países responsáveis } \\
\hline Dados e Medidas (a) & 2010 & $\begin{array}{l}\text { Austrália, México, África } \\
\text { do Sul }\end{array}$ \\
\hline Regulação e Standard-Setting Bodies (b) & 2010 & UK, Indonesia, Índia \\
\hline Finanças de Pequenas e Médias Empresas & 2010 & Alemanha, Turquia, Coreia \\
\hline Proteção ao Consumidor e Educação Financeira & 2013 & Rússia, EUA, China \\
\hline Mercados e Sistemas de Pagamento & 2014 & $\begin{array}{l}\text { Austrália, França, México, } \\
\text { África do Sul }\end{array}$ \\
\hline
\end{tabular}

(a) Atividades encerradas em 2014

(b) Inicialmente: "Princípios e Standard-Setting Bodies"

O G20, a quem a GPFI está subordinada, estabeleceu nove princípios para o que denominam como "Inclusão Financeira Inovadora”: liderança, diversidade, 
inovação, proteção, empowerment, cooperação, conhecimento, proporcionalidade, framework. Todos dizem respeito a formas de atuação e de relação entre governos e instituições privadas para o fomento de um mercado competitivo e sustentável de produtos e serviços financeiros para os pobres. Para seguir a pista dessas diretrizes que pretendem alcançar as mais variadas localidades do globo, escolhemos aquele que mais diretamente desenvolve a noção de que é preciso alterar regras e estruturas nos países, com atenção tanto para a abertura deste novo mercado quanto para requisitos que não coloquem o sistema financeiro em risco: o princípio de proporcionalidade. Diz ele:

Construir uma estrutura regulatória e de política que seja proporcional aos riscos e benefícios envolvidos em tais produtos e serviços inovadores e baseada na compreensão das lacunas e barreiras na regulação existente (FIEG, s/d: 12)

Termo pertencente ao universo das regulações financeiras, neste caso, a noção de proporcionalidade descreve a forma como as diretrizes para inclusão financeira desembarcam nos diversos países da GPFI. Isto é, destaca-se a importância de atentar à precisão da intervenção em cada país de forma a alterar ou estimular regras e procedimentos de maneira adequada aos objetivos de criação e circulação de produtos e serviços financeiros e, fator sempre mencionando, protegendo a estabilidade do sistema. Como discutido por Timmermans e Epstein (2010), nos quadros de uma sociologia da "standadização", a observação da criação de regras e padrões em níveis locais, regionais ou internacionais e sua disseminação em função de processos crescentemente globalizados ilumina aspectos menos evidentes de certos fenômenos. Este é o caso, sem dúvida: a incidência sobre leis e estruturas sociais e de mercado aparece também em outros princípios. No princípio de "inovação", por exemplo, menciona-se o uso de tecnologia ao lado de mudança institucional e, no de "cooperação", a construção de um ambiente que aproxime governos, negócios e outros atores considerados relevantes. O denominado "framework", por sua vez, acrescenta a necessidade de observação de padrões internacionais na garantia de uma série de outras diretrizes a efetivar e garantir. Esta ênfase atesta a necessidade, por essas organizações, de coordenação e controle das ações através de fronteiras nacionais. Elas requerem, ainda, um equilíbrio entre a homogeneização e flexibilidade para adaptação aos diversos ambientes locais. Os países orbitando no campo da GPFI são muito diferentes entre si e, no caso do Brasil, os documentos destacam, ainda, as diferenças internas, desaconselhando determinações únicas a serem aplicadas em meios tão diversos. 
A operacionalização do princípio de proporcionalidade ficou a cargo do subgrupo “Regulação e Standards Setting Bodies (SSB)". SSBs são organismos internacionais de normalização, isto é, estabelecem normas para controle, regulação ou padronização de determinadas áreas. Normas ISO (International Organization for Standardization) e da ABNT (Associação Brasileira de Normas Técnicas) são exemplos internacional e nacional, respectivamente, mais familiares ao público leigo. A parceira CGAP apresentou, em documento, quais seriam as SSBs priorizadas pela GPFI e o foco no contato com cada uma. São elas: o Comitê da Basileia para Supervisão Bancária, o Comitê para Sistemas de Pagamento e Liquidação, Força Tarefa para Ações Financeiras, Associação Internacional de Seguradoras de Depósitos e Associação Internacional de Supervisores de Seguros. A introdução do documento afirma que "juntas", as normas e diretrizes dessas cinco organizações "tem influência significativa sobre quantos domicílios pobres têm acesso a quais gama e qualidade de serviços financeiros e a qual custo" (CGAP, 2011: 1). Vê-se, assim, um uso instrumental do estabelecimento de regras e padrões que vai além do objetivo de normalização pura e simples. Embora processos de padronização possam ser vistos e tratados como neutros ou indiferentes a disputas entre interesses ou visões distintas, ao estimularem princípios, ordenarem práticas e atores, eles incidem sobre a realidade social, participando de suas configurações (Timmermans; Epstein, 2010: 75). Na mesma linha, Borraz (2004) analisa efeitos despolitizadores de processos de normatização na gestão pública, no contexto europeu. Ele mostra como o estabelecimento de regras e padrões pode criar, não apenas ordenar a posteriori, campos, objetos, condutas. No que nos interessa aqui, influenciar o acesso dos pobres ao mercado financeiro é um objetivo localizável no espaço e no tempo, formulado em fóruns específicos e restritos. Induzir sua realização por meio do estabelecimento de regras tem o efeito de dissimular esse traço, preservando a empreitada desde de sua total apreensão até de eventuais questionamentos.

A relação entre essas organizações e o Brasil é abordada em documento do mesmo ano, desta vez elaborado por outra organização parceira da GPFI, a Alliance for Financial Inclusion (AFI). O texto retoma o histórico de crises econômicas no Brasil na década de 1980, afirmando que essa experiência produziu duas características do Sistema Financeiro Nacional: aversão a risco e investimento das instituições financeiras menos na inovação de produtos e mais na "proteção de si próprias contra volatividade macroeconômica" (AFI, 2011: 1). Ambas, resultando em postura conservadora das instituições, poderiam interferir no passo da inclusão e por isso são apresentadas como potenciais pontos de trabalho no país. Medidas tomadas a partir da consolidação e expansão do Bolsa Família no 
começo dos anos 2000 são mencionadas como uma guinada neste contexto: "o Bolsa Famílias sintetiza esta virada política [dirigida à inclusão social] e alcançou notável sucesso (...)", como com a criação de contas simplificadas, de legislação favorável à expansão de correspondentes bancários e, adiantava o documento, a consideração, pelo MDS, de "iniciativas mais amplas de inclusão financeira, inclusive seguros, ligadas à base de dados do Bolsa Família” (AFI, 2011: 2).

\section{Antecedente da Inclusão Financeira: Microcrédito}

Para melhor dimensionamento da entrada do Brasil neste cenário por meio do Programa Bolsa Família é importante fazer menção, ainda que breve, ao papel cumprido pelo microcrédito no discurso internacional de combate à pobreza, desde a década de 1970. O marco obrigatório são as primeiras experiências do ainda desconhecido professor Muhammad Yunus, em Bangladesh, de pequenos empréstimos a indivíduos que, segundo sua observação, empreendiam ações que garantiam sua subsistência, mas não conseguiam expandi-las e manter uma atividade econômica estável. A experiência deu origem ao Grameen Bank, fundado em 1983.

$O$ entusiasmo da comunidade internacional com o microcrédito é atestado pela volumosa produção a respeito do tema (AFD, 1998). A criação do Comitê de Agências Doadoras para o Desenvolvimento de Pequenas Empresas, em 1979, é sua confirmação institucional e, após uma década de encontros regionais, realiza-se a Conferência Internacional sobre Desenvolvimento de Microempresas, proposta pelo Banco Mundial, que também secretariava o comitê (Levitsky, 1989: ix). O termo microempresa pode sugerir a ideia de empreendimentos mais estruturados do que o que está de fato no horizonte desta discussão. As falas da conferência revelam falta de consenso a respeito do entendimento e definição do que seria uma microempresa, mas algumas características consensuadas pelos presentes descrevem iniciativas bastante simples e precárias, como 0 trabalho familiar em áreas rurais ou indivíduos trabalhando sozinhos (que, na ausência de emprego formalizado, tornaram-se "auto-empregadores"), cooperativas de trabalhadores manuais ou prestadores de serviços que geram outras pequenas ocupações. Independentemente das definições de objeto e estratégias de intervenção, fica claro o interesse sobre um contingente de trabalhadores ora descritos como de baixa renda ora designados como informais.

A literatura que defende os resultados do microcrédito para melhoria da vida dos pobres também já recebeu revisão de diversas naturezas. Desde releituras que questionam metodologias empregadas (Duvendack et al., 2011; Roodman; Morduch, 2009), até análises que apontam efeitos negativos sobre as relações locais ou para o próprio mercado local (Ghosh, 2013; Bateman, 2010). O que 
interessa destacar, aqui, é a transformação de instituições dedicadas à operação destes pequenos empréstimos, originariamente não lucrativas, em instituições emprestadoras, atuando com taxas de juros semelhantes às dos mercados. Independentemente da diversidade de experiências que possa comportar essa transformação, elas são descritas pela literatura tanto em termos mais gerais (Bateman, 2010) quanto com base na experiência paradigmática e pioneira da Bolívia. Seu programa de microcrédito fazia parte de uma série de medidas tomadas em resposta aos efeitos negativos do pacote de medidas de ajuste estrutural - chamado Nova Política Econômica, de 1985 - e consequente crescente oposição ao governo. Uma organização não governamental, criada em 1987 e atuando no setor, a PRODEM, apresentou grande crescimento e foi transformada em instituição financeira, o Banco Solidário, ou BancoSol, em 1992 (Gonzales-Vega et. al, 1996).

A justificativa para isso que Bateman chama de "comercialização" dessas instituições foi o imperativo de que elas se tornassem financeiramente autossustentáveis, o que, com o tempo, passou de imperativo a algo desejável e bem-vindo, com apoio da comunidade internacional. $O$ autor mostra como essa transformação se deu às custas dos objetivos originais que remetem às iniciativas de Yunus e de outros antes dele, apesar das alegações de compatibilidade entre fins altruístas e maximização de lucros pela mesma instituição. O Brasil não ficou imune a esse movimento. A instituição das Organizações da Sociedade Civil de Interesse Público (OSCIPs), em 1999, permitiu que organizações não governamentais da área passassem a remunerar seus dirigentes e a cobrar taxas de juros do mercado. A história da primeira ONG brasileira voltada para o microcrédito - a União Nordestina de Assistência a Pequenas Empresas, UNO -, criada em 1973, é contada de forma que seu fechamento, após 18 anos de atividades, seja explicado pela não incorporação, por ela, da "autossustentabilidade a suas premissas de gestão" (Feltrim et. al., 2009: 16). Com referências específicas à experiência latino americana no cenário do microcrédito, essa narrativa adere ao diagnóstico de fundo da comercialização, ou seja, a necessidade de independência de recursos públicos nacionais e internacionais, radicalizando-o na defesa da separação entre "assistencialismo" e rentabilidade dessas instituições e do setor como um todo (Feltrim et al., 2009: 17).

Essas mudanças aconteceram ao longo dos anos de 1990 e, a despeito delas e das revisões, o tema do microcrédito entra nos anos 2000 com força: 2005 foi declarado o Ano Internacional do Microcrédito e Mohamad Yunnus foi ganhador do Nobel da Paz no ano seguinte, consolidando o título de banqueiro dos pobres. Considerando a síntese entre negócios e discurso social que este campo se mostrou capaz de empreender, a ideia do congressista norte-americano, Benjamin Gilman, na Conferência Internacional de 1988, de que "um dos segredos 
mais bem guardados do desenvolvimento logo se tornará conhecimento público, a saber, investir nos pobres é um bom negócio. Não só os pobres são bancarizáveis, eles podem ser um dos mais produtivos e seguros investimentos hoje” (Levitsky, 1989: xvii) parece ter ganhado terreno.

\section{Transferência de renda e 0 alcance dos mais pobres pelas finanças}

Em outubro de 2003, o Bolsa Família reuniu quatro programas de transferência de renda do nível federal: o Bolsa Escola, o Bolsa Alimentação, o Programa de Erradicação do Trabalho Infantil e o Vale Gás. Para isso, a criação de um Cadastro Único foi fundamental. O CadÚnico é um sistema de informações que armazena e permite processamento de dados relativos às famílias de baixa renda no Brasil. Antes da unificação, os programas eram geridos por órgãos e critérios distintos e cadastravam beneficiários separadamente, operando benefícios também diferentes. No novo formato, as informações estão centralizadas e acessíveis a quaisquer outras políticas e programas voltados para este público. ${ }^{5}$ Essa unificação implicou esforços intersetoriais para a definição de conceitos, critérios e procedimentos de coleta, armazenamento, atualização e processamento dos dados. A gestão é nacional, pela Secretaria Nacional de Renda de Cidadania (Senarc - Ministério do Desenvolvimento Social) e pela Caixa Econômica Federal; o contato com as famílias e coleta de dados é municipal.

Quadro 3 - Principais níveis e atribuições na gestão do Programa Bolsa Família (1)

\begin{tabular}{|l|}
\hline Ministério Desenvolvimento Social \\
\hline - Formulação de procedimentos e \\
instrumentos de gestão; \\
- Apoio técnico e financeiro a \\
estados e municípios; \\
- Disponibilização de canais de \\
comunicação a gestores(as) e \\
beneficiários(as); \\
- Articulação com outros órgãos e \\
integração de ações complementares; \\
- Monitoramento e avaliação do \\
Programa.
\end{tabular}

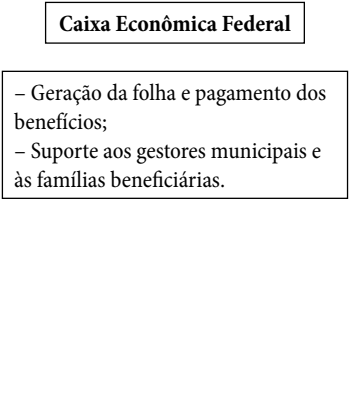

\begin{tabular}{|l|}
\multicolumn{1}{|c|}{ Municípios } \\
\hline - Articulação com as áreas \\
de educação, saúde - no \\
acompanhamento das \\
condicionalidades - e com a \\
assistência social, no acompanhamento \\
de famílias beneficiárias; \\
- Gestão de benefícios; \\
- Execução dos recursos financeiros; \\
- Acompanhamento e fiscalização \\
das ações; \\
- Fortalecimento do controle e da \\
participação social. \\
\hline
\end{tabular}

(1) A estrutura e dinâmica do Programa Bolsa Família são complexas, de modo que esta figura descreve apenas as principais ações. Informações disponíveis em: <http://mds.gov.br/ assuntos/bolsa-familia/gestao-do-programa/atribuicoes-de-cada-nivel-de-governo $>$. Acesso em: 08 jan. 2018. Para detalhes, consultar: Brasil, 2017; Soares; Sátiro, 2009; Escobar, 2008.

5 Relatório de Informações Sociais de acesso público informava 26.458.633 famílias (ou 75.661.727 pessoas) inscritas no Cadastro Único em novembro de 2017. 
Na criação do programa, o governo definiu meta de alcançar 11 milhões de famílias, o que ocorreu em 2006. Estudo do CGAP afirma que a aposta do governo era a de que o "acesso financeiro" permitiria a construção de ativos, pelos beneficiários, levando, por sua vez, à sua saída do programa (CGAP, 2010: 3). Um aspecto inovador do PBF, no plano das políticas sociais brasileiras, foi a vinculação do benefício ao nome das mulheres. Este procedimento remete às experiências internacionais de microcrédito, em que as mulheres são público preferencial. O que é apontado como papel desempenhado por elas no âmbito doméstico - postura e condutas na gestão do dinheiro - aparece também no discurso da inclusão financeira, fazendo delas clientes preferenciais ao lado de jovens e imigrantes, "setores da população em que os maiores ganhos podem ser produzidos" e cuja inclusão deve ser acompanhada de ações de educação e de proteção ao consumidor (GPFI, 2014: 4). Outra inovação do Bolsa Família foi o uso bem-sucedido da tecnologia bancária, que permitiu o depósito do recurso em conta de que o beneficiário poderia fazer a retirada diretamente, por meio de cartão magnético. Ela construiu nova forma de chegar ao público atendido, diferente do tradicional repasse por meio de vários níveis e camadas burocráticas. Esta característica foi celebrada pelo governo e partidários do programa por diminuir os riscos de uso clientelista do programa, no nível local, e por conferir agilidade e economia ao processo de pagamento (o custo de pagamento do Bolsa Família foi diminuído em sete vezes com o emprego dos cartões, segundo Lindert et al., 2007: 113).

A constituição deste cenário mostrou-se afim ao que vinha sendo construído e seria batizado como inclusão financeira. O número de postos de atendimento bancário - agências ou comércio local autorizado a realizar alguns serviços, postos de atendimento, caixas eletrônicos - dobrou entre 2002 e 2008, passando de 82,1 mil a 117,6 mil (Levorato, 2009: 173). Os pontos de comércio - padarias, casas lotéricas, correios - que realizam operações bancárias como pagamento de contas, depósitos e retiradas, concessão de crédito, entre outros, são chamados de correspondentes e foram criados entre as décadas de $1960 \mathrm{e}$ 1970 (a data varia com a fonte consultada). A legislação reguladora desse tipo de serviço recebeu alteração, bem como as regras relativas aos empréstimos consignados. É de 2003, também, a legislação que cria as contas corrente e poupança simplificadas, cujas características respondem ao objetivo de facilitar a abertura de contas bancárias pela população mais pobre. Entre as principais, estão a apresentação de menos documentos para abertura e isenção tarifária na prestação de determinados serviços. A relevância da bancarização, do ponto de vista do sistema financeiro, é o de que, a partir dessa entrada, outros produtos 
podem ser oferecidos. Estudo de 2012 indicava que " $40 \%$ dos clientes do Bolsa Família usam pelo menos mais um produto do banco", da Caixa Econômica Federal, no caso (Bold et al., 2012: 22).

Não é intenção estabelecer relação de causa e efeito entre discursos e medidas tomadas nos planos internacional e nacional, isto é, entre medidas e discursos do Bolsa Família e diretrizes e discursos produzidos pela GPFI e seus parceiros. Falamos em afinidade com a intenção de propiciar a consideração de que as fronteiras entre eles e no interior de cada um são porosas e abertas a composições nuançadas e nem sempre óbvias. Se é verdade que ocorre um movimento de apropriação por esta última dos resultados produzidos pelo Programa (não é demais lembrar que são iniciativas originadas entre atores financeiros, inclusive a congênere nacional PNIF), de forma a explorar um canal de introdução de sua agenda no plano interno, por outro, a pluralidade de concepções em torno da transferência de renda (democratização da riqueza gerada socialmente ou política de corte liberal?) abre espaço para níveis variados de reações de rejeição e de identificação, em relação ao ideário da inclusão financeira. As palavras do então ministro da Secretaria de Assuntos Estratégicos da Presidência da República (2013-2015) são exemplos dessa última: a inclusão financeira permitiria "ir além e 'dar o mercado aos pobres', completando o movimento dos últimos anos [refere-se ao $\mathrm{PBF}$ ], quando, pela via da queda da desigualdade, 'demos os pobres aos mercados (consumidores)'” (Neri, 2014: 731). Na mesma publicação, entretanto, a ideia de inclusão produtiva, formulada mais tardiamente, ${ }^{6}$ chega mesmo a trabalhar com noções que se pretendem alternativas ao mercado, mobilizando referências distintas (Singer et al., 2014). No que tange ao campo das finanças, o relatório da AFI, há pouco citado, sobre as relações entre SSBs e o Brasil (AFI, 2011), menciona dificuldades a superar na facilitação do acesso ao sistema bancário: de um lado, a flexibilização de processos de identificação de clientes quando da abertura de conta levou a que o país tivesse avaliações negativas por certos órgãos normalizadores, como foi o caso com a Força Tarefa para Ações Financeiras (ou GAFI, Grupo de Ações Financeiras, no Brasil), dedicada ao combate de lavagem de direito e de financiamento de ações terroristas. Por outro lado, observou-se que mesmo com leis permitindo essa flexibilização, algumas instituições financeiras brasileiras resistiam em adotá-las, por diferentes motivos. Seria necessário, então, perspectiva adotada

6 Essa observação tem a intenção de deixar registrado um aspecto institucional que, entretanto, não altera nosso argumento. As referidas discussões se deram no âmbito do Plano Brasil sem Miséria, de 2011. Com o fim de eliminar a pobreza extrema, o Plano abarca o Bolsa Família. O lugar do PBF no Plano pode ser conferido em Osorio e Soares (2014). 
no relatório, alinhar todas as organizações envolvidas ao objetivo comum de ampliação do sistema financeiro ou, nos termos adotados, de inclusão financeira, desde o organismo internacional até a instituição bancária operando na ponta da cadeia.

Em 2008, o governo brasileiro decidiu atuar de forma mais incisiva e o MDS criou, juntamente com a Caixa Econômica Federal, o Projeto de Inclusão Bancária. Material informativo (sem data, mas com dados de até 2011) produzido pela Senarc definia-lhe quatro objetivos:

(...) reduzir a desigualdade do acesso a serviços financeiros, decorrente da má distribuição de renda do país"; propiciar condições para a sustentabilidade econômica das famílias beneficiárias do PBF; prover acesso aos produtos e serviços bancários e fomentar a Educação Financeira.

Com exceção da menção explícita às famílias do Bolsa Família, os três objetivos são semelhantes aos apresentados pela PNIF (ver Item 1). Mais uma vez, é preciso colocar esse processo de interiorização do sistema financeiro em perspectiva para que sua importância seja corretamente dimensionada. $\mathrm{Na}$ análise de Weber (2004) sobre a articulação entre objetivos de liberalização das finanças e alterações nas barreiras existentes à sua circulação, por meio do microcrédito e seus discursos de disponibilização de recursos para o fim da pobreza, a autora conta como, em 1992, o Banco Mundial adotou uma Diretiva Operacional em resposta ao desafio de ampliar seus negócios no campo das finanças. A Diretiva colocava como objetivo, entre outros, acelerar a ampliação do mercado financeiro por meio da introdução de novos instrumentos, serviços e produtos para novos usuários. A "incerteza" sobre como colocar os objetivos em prática levou à revisão da Diretiva e sua reformulação foi eficaz na medida em que resolveu "problemas de implementação, revisando a estratégia de forma a construir o link entre os níveis micro e macro da política do setor financeiro, ao colocar ênfase no microcrédito baseado em programas para 'redução da pobreza'" (Weber, 2004: 372). Isto é, alcançar o usuário final, quando se fala em populações de baixa renda, não é tarefa banal. O livro de Prahalad (2005) é sempre citado quando o assunto é criação de mercados para os pobres, muito em função de tratar do assunto de forma pragmática: os empresários deveriam redefinir suas concepções e modelos de negócio para atingir as camadas ainda inexploradas da população, a base da pirâmide, e as mediações institucionais teriam papel central nisso. O Projeto de Inclusão Bancária exibe operações implicadas nesta tarefa. Daí a relevância da estrutura descentralizada da burocracia estatal e do volume de informações sobre 
a localização e característica dessa população centralizado no CadÚnico. A partir daí é possível avançar.

Considerando o contexto nacional, podemos tomar a análise de Singer a respeito dos governos Lula, segundo a qual os anos pós-crise financeira de 2008 foram de "estímulo ao mercado interno e uso intensivo dos bancos públicos" (Singer, 2012: 152). A transferência de renda, o aumento do salário mínimo e as facilidades de crédito tiveram papel importante para o primeiro. Por outro lado, os dois períodos anteriores também abarcam medidas que favoreciam as finanças populares, fosse com o equilíbrio pendendo mais para o desenvolvimentismo, entre 2006 e 2008, ou com adoção de medidas, também segundo Singer, de sentidos contrários, entre 2003 e 2005: de feição neoliberal, atendendo a interesses de mercado em concomitância com outras de cunho social, voltadas para a população pobre: criação do Bolsa Família, valorização do salário mínio e expansão do financiamento popular (Singer, 2012: 144 e ss.). Dada a centralidade atribuída ao problema da pobreza e o perfil das políticas que a acompanharam, no período analisado pelo autor (e pode-se dizer que nos seguintes também), a direção tomada mostra coerência com o ambiente internacional, em especial com o campo da inclusão financeira. Mais uma vez, no sentido da porosidade e afinidade em torno de medidas tomadas e resultados obtidos, que aproximam atores independentemente de seus fins.

O esforço de inclusão bancária resultou em novo leque de ações, com objetivo de preparar as agências, seus profissionais e as próprias famílias para a entrada desse público no sistema financeiro. Sem entrarmos no ramo das ações executadas pela Estratégia Nacional de Educação Financeira, em curso desde 2010 (Bruhn et al., 2013), a própria Caixa Econômica Federal produziu cartilhas com conteúdo relativo a finanças pessoais e familiares. ${ }^{7}$ Por meio de parcerias com organizações sociais atuantes no nível local, esses conteúdos chegavam até a população alvo (CEF, 2009). Além das informações básicas sobre serviços e nomenclaturas das agências bancárias, eles descrevem também posturas e comportamentos que devem ser cultivados e valorizados, como autocontrole, empreendedorismo e previdência, ainda que em terreno tão sensível quanto o de gestão do dinheiro em ambiente doméstico. A ideia de que o desregramento ou

7 Existem muitas atividades com o fim de informar e formar indivíduos para a aquisição de produtos e serviços financeiros. Entretanto, um Decreto Federal de 2010 (7397/2010) criou a Estratégia Nacional para Educação Financeira (ENEF), reunindo instituições do mercado financeiro e órgãos públicos para desenvolver ações específicas, em consonância com o cenário aqui descrito acerca da inclusão financeira. Por envolver estrutura, história e diretrizes próprias, a ENEF não será objeto deste artigo. As ações educativas promovidas pela Caixa Federal são suficientes para compor nossa discussão. 
a imprudência estejam na origem de uma situação de pobreza familiar subjaz as afirmações feitas no material educativo: "Atitudes são tão importantes quanto conhecimento. Nunca gaste mais do que ganha. Procure ganhar mais" (CEF, 2009: 5). A definição de crédito também faz menção à correção nas relações e cultivo de uma atitude valorizada a priori:

Quando uma pessoa merece a confiança de outras, dizemos que ela 'tem crédito, ou seja, outras pessoas acreditam nela, sabem que ela vai pagar o que deve. (...) Pessoas que dispõem de credibilidade, isto é, uma situação ou história de vida que faz com que outras pessoas ou empresas tenham confiança nelas, conseguem comprar produtos e serviços, mesmo sem ter todo o dinheiro necessário (CEF, 2009: 8).

Esse tipo de afirmação produz a ideia de responsabilização individual pela precariedade financeira. Por outro lado, o alerta para o gasto regulado ao ganho aparece junto da capacidade de compra sem os recursos necessários para tal como sinal de algo positivo, mérito e reconhecimento anteriores. A ideia da incapacidade de garantir bem-estar à família aumenta ainda mais a conotação moral do julgamento imposto aos indivíduos desta classe social. Não que fosse necessário. Estudos sobre práticas financeiras de indivíduos e famílias a quem essas políticas são dedicadas mostram claramente que as relações com o dinheiro e o endividamento são complexas, permeadas por elementos outros que não apenas os advindos da vida econômica. Poupança e aumento no consumo, prestígio e desmoralização nos círculos de sociabilidade não são estabelecidos como vias de mão única com relação ao acesso às finanças (Müller, 2009; Collins et al., 2009). Socialmente, entretanto, aqueles conteúdos normativos ganham novo canal de disseminação e reiteram noções de uma meritocracia tanto questionada quanto mobilizada ao longo da história de conflitos distributivos de recursos simbólicos e materiais.

Pode-se alegar que tal discurso decorre do fato de que estamos tratando de uma instituição financeira que tem interesses econômicos semelhantes aos de bancos privados. Isto é, se oferecem crédito e outros serviços a clientes que representam risco a seu negócio, têm o direito de produzir as prevenções que acharem necessárias. A proteção à instituição, à estabilidade do sistema se sobressai à do cliente. Por outro lado, é fato que esse discurso é justificado, nos documentos que se aproximam dos conteúdos de educação financeira, pela proteção do novo cliente, argumento mais envolvente e sedutor. Declarações de profissionais do banco vão nesse sentido, tratando de afirmar que a Caixa tem uma função pública na sociedade, além de suas prerrogativas de 
negócio. De qualquer maneira, esses discursos e transformações vêm atravessando a realidade social, cortando-a verticalmente e produzindo efeitos em vários níveis, desde a financeirização das políticas sociais descrita por Lavinas, a constituição da renda como bem-estar de que fala Trumbull ou a invenção de novas categorias definidoras das relações dos indivíduos com as estruturas da vida coletiva, como as cidadanias "capitalista" (Soares; Sobrinho, 2008: 45), "fiscal" (Banco do Brasil, 2013: 21) ou "financeira" (Banco Central do Brasil, 2015).

\section{Um mercado financeiro para os pobres}

A inclusão financeira, como a descrevemos aqui, pode ser lida como uma nova etapa na história da relação entre Estado e mercado - agora pela porção crescentemente importante deste último, a financeira -, no tocante ao tratamento dos grupos pauperizados. No caso brasileiro, o acesso da política federal de transferência de renda ao contingente mais pobre da população significou concomitante acesso do mercado a este público. Se em outros países, décadas antes, as organizações sociais de microcrédito cumpriram esse papel, tornando-se, posteriormente, instituições financeiras de mercado, o Bolsa Família, por sua vez, organizou, desde o desenho no nível centralizado de sua gestão, até os órgãos descentralizados da estrutura da política da assistência social, o alcance dos pobres e a produção de conhecimento sobre eles. Trata-se de movimento em via de duas mãos. A unificação das informações até então restritas ao nível local, independentemente das formas de seu uso concreto pelas instituições que as acessaram, consolidam, no espaço público, a existência de um contingente populacional até então não-visível ou de relevância fragmentada, geograficamente limitada. Por outro lado, o "ambiente financeiro" também apresentou mudanças, se capilarizando e, assim, multiplicando sua presença em áreas remotas. Por ordinária que pareça, essa pulverização requer alterações em leis e criação de novas estruturas que supervisionem, regulem e controlem os agentes que a concretizam. Requer a construção de narrativas, justificativas, formas de olhar e apreender a realidade.

A despeito da pluralidade de atores institucionais identificados neste campo, a ideia de que 0 acesso a bens e serviços financeiros, pelos pobres, os beneficiará, permitindo-lhes proteção em situações de imprevisto e risco, como doença ou desemprego, ou recompensas em caso de investimento, seja em formação, seja no desenvolvimento de um negócio próprio, é consensual. A adesão a ela atesta o desgaste sofrido por noções de políticas universais e gratuitas, processo mais 
antigo. As condições que sustentam as ações e discursos em nome da inclusão financeira, no Brasil, hoje, são tributárias de uma história cujas origens estão anunciadas já nos anos de abertura democrática. Ou seja, é preciso considerar a progressiva designação pública dos problemas sociais por suas formas mais extremas e urgentes. Se subdesenvolvimento e injustiças sociais foram molduras epistemológicas dentro das quais se davam os embates a respeito das formas de distribuir riqueza e produzir igualdade, dos anos de 1990 em diante foram os temas da fome, da pobreza e da miséria a definirem parâmetros cada vez mais segmentados e individualizados para esses julgamentos. Para isso, o avanço técnico que produziu extenso cardápio de instrumentos de focalização, localização, mensuração de fenômenos sociais e políticas também teve importância, traduzindo essas novas concepções em meios de ação.

Outro vetor do processo a considerar diz respeito à maneira como um conglomerado de instituições internacionais incide sobre definições políticas internas. A inclusão financeira configura-se como um grande esforço de organização de atores e ideias que já atuavam, mais dispersamente, na linha da liberalização das finanças. Daí que a quantidade de ramos de atuação seja tão grande e variada. Documentos produzidos pelas organizações internacionais da GPFI têm discurso afinado entre si e o delas com o das instituições brasileiras. Tratando-se de "alianças" e "parcerias", as "diretrizes" e "lições aprendidas" aí produzidas pertencem a um mundo que não necessariamente o das leis e compromissos firmados entre países e mediados por organizações tradicionais. A fluidez da GPFI se traduz na fluidez dessas recomendações e é preciso mais pesquisas para acompanhar a evolução da presença do Brasil neste âmbito.

O processo em curso não está livre de recuos e ajustes. Nem a agência-barco da Caixa Econômica Federal ${ }^{8}$ nem a resistência de instituições financeiras em aderir à facilitação de abertura de contas bancárias deve ser considerada isoladamente. Segundo indicam documentos dos assim chamados parceiros internacionais, há que se trabalhar para desatar eventuais nós em espaços nacionais. A passagem de recursos pelo mundo tecnológico dos mercados financeiros dá unidade a essa diversidade. Para isso, ou com isso, vão-se gestando também novos valores e comportamentos, cultura e compreensões da sociedade e do mundo em que vivemos.

8 Trata-se de uma embarcação utilizada para a prestação de serviços bancários a populações ribeirinhas no Amazonas e no Pará. Segundo informações da Caixa, serviços públicos também eram prestados utilizando o mesmo meio, como projetos da Secretaria Nacional de Políticas para as Mulheres e atendimentos pelo Ministério do Trabalho. 


\section{Referências}

AFD - Agence Française de Développement. Bulletin Bibliographique Thématique Micro-Entreprises et Micro-Financement. n. 2, 1998.

AFI - Alliance for Financial Inclusion. O 'jeito brasileiro' - the Brazilian way. Brazil's engagement with standards setting bodies and the implications for financial inclusion, 2011. Disponível em: <http://www.gpfi.org/sites/default/files/documents/Brazil\%E2\%80\%995\%2oEngagement\%20with\%20Standard\%20Setting\%20 Bodies\%2oand\%2othe\%2oImplications\%2ofor\%2oFinancial\%2oInclusion.pdf.> Acesso em: 30 jun. 2016.

BANCO DO BRASIL. Brasil: Implementando A Estratégia Nacional de Educação Financeira. Brasília: Banco do Brasil, 2013.

BATEMAN, Milford. Why Microfinance Doesn't Work? The Destructive Rise of Local Neoliberalism. London/New York, Zed Books, 2010.

BOLD, Chris et al. Transferência social de renda e inclusão financeira: evidências de quatro países. Enfoques n. 77, CGAP, 2012. Disponível em: <http://www-wds.worldbank.org/external/default/WDSContentServer/WDSP/IB/2014/04/29/00046925 2_20140429164346/Rendered/PDF/68070oBRIoPORTooBox377351BooPUBLICo. pdf. >. Acesso em: 06 jun. 2016.

BORRAZ, Olivier. Les normes: instruments dépolitisés de l'action publique. In: LASCOUMES, Pierre; LE GALĖS, Patrick. (Orgs.) Gouverner par les instruments. Paris, Sciences Po, 2004.

BRUHN, Mirian et al. O Impacto da Educação Financeira do Ensino Médio Evidência Experimental do Brasil. Washington, DC, Banco Mundial, 2013.

CEF - Caixa Econômica Federal. Fundamentos de Educação Financeira. Brasília: Caixa, 2009.

Bolsa Família inclui 2,1 milhões de brasileiros no sistema bancário. Notícias Caixa, 2009. Disponível em: <http://www1.caixa.gov.br/imprensa/noticias/asp/popup.asp?codigo=6610386>. Acesso em: 12 nov. 2018.

CGAP. Consultative Group to Assist the Poor. Update on Regulation of Branchless Banking in Brazil, 2010. Disponível em: <http://www.cgap.org/sites/default/files/ CGAP-Regulation-of-Branchless-Banking-in-Brazil-Jan-2010.pdf>. Acesso em: 30 jun. 2016.

CGAP. Global Standard-Setting Bodies and Financial Inclusion for the poor. Toward proportionate standards and guidance, 2011. Disponível em: <http://www.gpfi. org/sites/default/files/documents/CGAP.pdf >. Acesso em: 30 jun. 2016.

CHIAPELLO, Ève. Financialisation of Valuation. Human Studies, v. 38, n. 1, mar. 2015, pp. 13-35. 
COLLINS, Daryl et al. Portfolios of the poor: how the world's poor live on two dollars a day. Princeton, Princeton University Press, 2009, 296 p.

DARDOT, Pierre; LAVAL, Christian. La Nouvelle Raison du Monde. Paris, La Découverte, 2009, $504 \mathrm{p}$.

DUMÉNIL, Gérard; LEVY, Dominique. Costs and benefits of neoliberalism. A class analysis. Review of International Political Economy, v. 8, n. 4, dez. 2001, pp. 578-607.

DUVENDACK, Maren et al. What is the evidence of the impact of microfinance on the well-being of poor people? London, EPPI-Centre, Social Science Research Unit, Institute of Education, University of London, 2011.

ESCOBAR, Cecília Maria da Souza. Governança estratégica em redes de políticas públicas: a experiência do Programa Bolsa Família. Dissertação de mestrado, Ciência Política, Universidade de Brasília, 2008.

FIEG - Financial Inclusion Experts Groups. G2o Financial Inclusion Action Plan, s/d. Disponível em: <http://gpfi.org/sites/default/files/documents/G20\%20 Financial\%2oInclusion\%2oAction\%2oPlan.docx.pdf >. Acesso em: 30 jun. 2016.

G20. Leader's statement: The Pittsburgh Summit, 2009. Disponível em: <http:// ec.europa.eu/archives/commission_20102014/president/pdf/statement_20090826_ en_2.pdf>. Acesso em: 30 jun. 2016.

GHOSH, Jayati. Microfinance and the challenge of financial inclusion for development. Cambridge Journal of Economics, v. 37, n. 6, nov. 2013, pp. 1203-1219.

GONZALES-VEGA, Claudio et al. BANCOSOL - The Challenge of Growth for Microfinance Organizations. Ohio, Economics and Sociology Occasional Paper n. $2332,1996$.

FLIGSTEIN, Neil; GOLDSTEIN, Adam. The Emergence of a Finance Culture in American Households. Socio-Economic Review, v. 13, n. 3, jul. 2015, pp. 575-601.

HAN, Clara. Life in Debt. Times of care and violence in neoliberal Chile. Berkeley, University of California Press, 2012, 298 p.

KRIPPNER, Greta R. The Financialization of the American Economy. Socio - Economic Review, v. 3, n. 2, maio 2005, pp. 173-208.

LAVINAS, Lena. A financeirização da política social: o caso brasileiro. Politika. Rio de Janeiro, n. 2, 2015, pp. 35-51.

LEMOINE, Benjamin. Discipliner l'État par la dette. La mise em marché et la sectorisation du "probléme" de la dette publique. In: HALPERN, Charlotte et al. (orgs.) L'instrumentation de l'action publique: controverses, résistences, effets. Paris, Presses de Sciences Po, 2014, pp. 367-395.

LEVORATO, Wilson Roberto. Microfinanças e o sistema bancário brasileiro. In: FELTRIM, Luiz Edson et al.(orgs.) Projeto Inclusão Financeira. Perspectivas e 
desafios para Inclusão Financeira no Brasil: visão de diferentes atores, Brasília, Banco Central, 2009, pp.171-187.

LEVITSKY, Jacob. Microentreprises in developing countries. London, IT Publications, 1989 (274).

LINDERT, Kathy et al. The Nuts and Bolts of Brazil's Bolsa Familia Program: Implementing Conditional Cash Transfers in a Decentralized Context. Washington DC, World Bank Social Protection Paper n. 709, 2007.

MÜLLER, Lucia Helena Alves. "Então eu fui à luta!": repensando as representações e práticas econômicas de grupos populares a partir de uma trajetória de ascensão social. Política \& Sociedade. Santa Catarina, v. 8, n. 15, set. 2009, pp. 145-171.

NERI, Marcelo. O Programa Bolsa Família e a Inclusão Financeira. In: CAMPELLO et al. (coord.). O Brasil sem Miséria, Brasília, MDS, 2014.

OSORIO, Rafael Guerreiro; SOARES, Sergei S. D. O Brasil sem Miséria e as mudanças no desenho do Bolsa Família. In: CAMPELLO et al. (coord.). O Brasil sem Miséria, Brasília, MDS, 2014.

PNIF - Parceria Nacional para Inclusão Financeira. Plano de Ação para Fortalecimento do Ambiente Institucional. Brasília, Banco Central, 2012.

PRAHALAD, Coimbatore Krishnarao. The Fortune at the Bottom of the Pyramid. Eradicating Poverty Through Profits. NJ, Pierson Education/ Wharton School Publishing, 2005.

ROODMAN, David; MORDUCH, Jonathan. The Impact of Microcredit on the Poor in Bangladesh: Revisiting the evidence, CGD Working Paper 174. Washington, DC, Center for Global Development, 2009.

SEIBEL, Hans Dieter. Does History Matter? The Old and the New World of Microfinance in Europe and Asia - Working paper, Köln: Development Research Center, University of Cologne, 2005.

SINGER, Paul; SILVA, Roberto Marinho Alves da; SCHIOCHET, Valmor. Economia Solidária e os desafios da superação da pobreza extrema no Plano Brasil Sem Miséria. In: CAMPELLO et al. (coord.). O Brasil sem Miséria, Brasília, MDS, 2014. SOARES, Mardem Marques; SOBRINHO, Abelardo Duarte de Melo. Microfinanças O papel do Banco Central do Brasil e a importância do cooperativismo de crédito. Brasília, BACEN, 2008.

SOARES, Sergei; SÁTYRO, Natália. O Programa Bolsa Família: desenho institucional, impactos e possibilidades futuras - Texto para Discussão n. 1424. Brasília, IPEA, 2009.

TIMMERMANS, Stefan; EPSTEIN, Steven. A World of standards but not a standard world: toward a Sociology of Standars and Standardization. The Annual Review of Sociology, California, v. 36, ago. 2010, pp. 69-89. 
TRUMBULL, Gunnar. Credit Access and Social Welfare: The Rise of Consumer Lending in the United States and France. Politics \& Society, v. 40, n. 1, 2012, pp. 9-34.

WEBER, Heloise. The 'new economy' and social risk: banking on the poor? Review of International Political Economy, v. 11, n. 2, 2004, pp. 356-386.

Recebido em 24/04/2017

Aprovado em 19/02/2018

\section{Como citar este artigo:}

CUNHA, Márcia Pereira. Silencioso e penetrante: o processo de financeirização a partir das instituições promotoras da inclusão financeira. Contemporânea - Revista de Sociologia da UFSCar, v. 8, n. 2, jul.- dez. 2018, pp. 585-606. 